\title{
Mechanical and Metallurgical Properties of Heavy Wall Grade X80 High Strain Line Pipe Steel
}

\author{
Weihua Sun ${ }^{1, *}$, Ping Du ${ }^{1}$, Zhigang Liu ${ }^{1}$, Chaohai Guo ${ }^{1}$, Runsheng Zhang ${ }^{1}$, Lei Zhang ${ }^{2}$, \\ Jinghui Ren², Liwei Liu' \\ ${ }^{1}$ Jinan Steel Company, Shandong Iron and Steel Group Co., Ltd, China \\ ${ }^{2}$ Julong Steel Pipe Co., Ltd, China
}

Copyright $(\subset) 2015$ by authors, all rights reserved. Authors agree that this article remains permanently open access under the terms of the Creative Commons Attribution License 4.0 International License

\begin{abstract}
Mechanical and metallurgical properties of a $27 \mathrm{~mm}$ thick Grade X80 steel plate and its UOE pipe are described in this paper. The steel is economically designed for its chemical compositions. Steel plates were produced by Thermal-mechanical processing (TMCP) with attentive reduction control during hot rolling stage. The microstructure is composed of multi-phases in which polygonal ferrite and granular bainite are the principal constituents. Line pipes of $1219 \mathrm{~mm}$ outer diameter, which has strain based design for long distance natural gas transportation over the permafrost and seismic areas, were manufactured by the UOE process under a $0.8 \%$ expanding ratio on the pipe. Mechanical properties of the pipe and in the girth weld joints comply well with the pipeline construction requirement. Precipitation behaviors were analyzed in the steel materials, and a strengthening contribution at about 45.6 $\mathrm{MPa}$ is disclosed. Dislocation hardening in the pipe base materials after the simulating coating gives rise to 44.9 MPa.
\end{abstract}

Keywords Line Pipe, Strain Based Design, Dual Phase Microstructure, Uniform Elongation, DWTT Toughness, TMCP

\section{Introduction}

There is very a constant lack of proximity between the most attractive natural gas fields and its global consumers. The on-shore long distance gas transportation by pipeline often goes through harsh climates and complicated regional geological areas. For instance, the West-East gas pipeline engineering across China is close to earthquake zones and permafrost areas. In such cases, the pipeline is exposed to complicated stress conditions and should be able to withstand the imposed installation or environmentally tensile strains to ensure its integrity. Therefore, it is important to ensure that the maximum allowable global strain is greater than the strain imposed on the pipeline. To this end, the original pipeline design scheme based on stress is not suitable [1-2]. As a result, people put forward the strain based design concept on account of pipeline integrity assessment. Meanwhile, high strength pipeline steels X70 and beyond with sufficient toughness and ductility are needed to improve transportation capacity. Therefore, it is essential that the pipeline steel for manufacturing pipeline should have high strength, high longitudinal uniform elongation, low yield to tensile ratio and well girth welding performance etc. [3-5].

Nowadays, thermal-mechanical controlled processing (TMCP) is the most effective technology to produce high strength pipeline steels that are typically low-carbon steels micro-alloyed with niobium, vanadium, titanium copper, nickel, molybdenum etc. in order to suppress austenite recrystallization and to obtain precipitation hardening during the hot steel processing [6-12]. Recent studies indicated that Bainite-Ferrite dual-phase microstructure controlled by TMCP is known as a typical microstructure constituent effective in reaching the target strength, toughness and ductility for strain-based design pipeline applications [1-4, 13-15]. It is also reported that the heat-treatment on-line process (HOP) in JFE reveals improved mechanical performance in comparison to conventional high strain pipeline steels [4-5, 14-15]. The HOP, as the name suggests, introduces an on-line heat-treatment system to control steel microstructure transformation, carbide precipitation and second phase formation by interrupting the accelerated cooling process at an intermediate temperature. However, there is also considerable interest to reduce construction cost for long distance pipeline as well as costs relating to safety and reliability of gas transportation among the pipeline steel supplier and the pipeline engineer.

In this paper, $27 \mathrm{~mm}$ thick molybdenum and boron free Grade X80 high strain steel plate, was developed to reduce materials manufacturing cost. Steel plates were manufactured in a double 4-high plate mill that is equipped with Multipurpose Interrupted Cooling Process (MULPIC). 
Reductions of the slabs were controlled to be no less than $76 \%$ under the non-recrystallization temperature. The steel plates were delayed from 70 to $110 \mathrm{~s}$ between finishing rolling and starting accelerated cooling according to the environment temperature to control the microstructure constituent. Microstructure of the steel plates is characterized as polygonal ferrite and granular bainite in principal. The pipeline with outer diameter of $1219 \mathrm{~mm}$ was manufactured by UOE process with a $0.8 \%$ expanding ratio. Work hardening behaviors are studied on the simulated strain aged pipeline base materials. Precipitation hardening performance of the microalloying elements are further analyzed on the steel plate.

\section{Chemical and Mechanical Properties of the X80 High Strain Steel Plate and the Steel Pipe}

Chemical Compositions of the Grade X80 Steel. The Grade X80 steel is microalloyed with $\mathrm{Cr}, \mathrm{Ni}, \mathrm{Nb}$, Ti and $\mathrm{Cu}$. Table 1 shows the chemical compositions for grade X80 high strain pipeline.
Mechanical Properties of Steel Plate and the Steel Pipe. Transversal and longitudinal tensile tests were carried out on the pipeline base materials. The transversal tensile tests were measured on the strip specimens. The longitudinal tests were on round bar specimens. Strain aging was carried out on the tensile testing coupons that were heated at $195^{\circ} \mathrm{C}$ to $205^{\circ} \mathrm{C}$ and kept for 5 minutes [15-18]. Table 2 displays the results, proving that both transversal and longitudinal tensile properties in the pipeline comply with the pipeline engineering requirements.

In Table $2, \mathrm{R}_{\mathrm{t} 0.5}$ reveals an average $109 \mathrm{MPa}$ and $51 \mathrm{Mpa}$ increase between the pipe base material and the steel plates respectively in transversal and longitudinal directions. $R_{m}$ appears to exhibit little changes between the plate material and the base material in the pipe in both directions. In comparison to plate material, value of area reduction $\left(\mathrm{A}_{50}\right.$ in the table) in the pipe material reduced $18 \%$ in the transversal direction while it increased $3 \%$ in the longitudinal direction. $\mathrm{R}_{\mathrm{t} 0.5} / \mathrm{R}_{\mathrm{m}}$, the yield-to-tensile ratio, proves 0.15 and 0.12 decrements respectively in transversal and longitudinal horizons. $\mathrm{R}_{\mathrm{t} 1.5} / \mathrm{R}_{\mathrm{t} 0.5}, \mathrm{R}_{\mathrm{t} 2.0} / \mathrm{R}_{\mathrm{t} 1.0}$ and the uniform elongation (UEL/\%) display reductions respectively at about $0.1,0.05$ and at a value of $4.4 \%$.

Table 1. Chemical Composition of the Grade X80 steel [wt\%]

\begin{tabular}{cccccccccccccc}
\hline & $\mathrm{C}$ & $\mathrm{Mn}$ & $\mathrm{Si}$ & $\mathrm{P}$ & $\mathrm{S}$ & $\mathrm{Mo}$ & $\mathrm{Cr}$ & $\mathrm{Cu}$ & $\mathrm{Ni}, \mathrm{V}, \mathrm{Nb}, \mathrm{Ti}$ & $\mathrm{Al}$ & $\mathrm{N}$ & $\mathrm{B}$ & $\mathrm{Pcm}$ \\
\hline Maximum & 0.10 & 1.85 & 0.45 & 0.025 & 0.015 & 0.50 & 0.50 & 0.50 & & - & 0.008 & 0.001 & 0.25 \\
Typical & 0.06 & 1.73 & 0.26 & 0.008 & 0.001 & 0.006 & 0.291 & 0.211 & 0.26 & 0.023 & 0.005 & 0.0002 & 0.19 \\
\hline
\end{tabular}

Table 2. Tensile Test Result of the Grade X80 Pipeline Steel Materials

\begin{tabular}{|c|c|c|c|c|c|c|c|c|c|}
\hline Direction & & Plate/Pipe & $\mathrm{R}_{\mathrm{t} 0.5}[\mathrm{MPa}]$ & $\mathrm{R}_{\mathrm{m}}[\mathrm{MPa}]$ & $\mathrm{A}_{50}[\%]$ & $\mathrm{R}_{\mathrm{t} 0.5} / \mathrm{R}_{\mathrm{m}}$ & $\mathrm{R}_{\mathrm{t} 1.5} / \mathrm{R}_{\mathrm{t} 0.5}$ & $\mathrm{R}_{\mathrm{t} 2.0} / \mathrm{R}_{\mathrm{t} 1.0}$ & UEL [\%] \\
\hline \multirow{7}{*}{ Transverse } & \multirow{3}{*}{ Plate } & Min. & 508 & 703 & 38 & 0.68 & & & \\
\hline & & Max. & 590 & 774 & 50 & 0.74 & & & \\
\hline & & Ave. & 537 & 751 & 42 & 0.71 & & & \\
\hline & \multirow{4}{*}{ Pipe } & Min. & 598 & 704 & 20 & 0.84 & & & \\
\hline & & Max. & 700 & 806 & 26 & 0.88 & & & \\
\hline & & Ave. & 646 & 751 & 24 & 0.86 & & & \\
\hline & & Required & $555-705$ & $625-825$ & API & 0.93 & & & \\
\hline \multirow{7}{*}{ Longitude } & \multirow{3}{*}{ Plate } & Min. & 477 & 687 & 42 & 0.64 & 1.17 & 1.09 & 10.0 \\
\hline & & Max. & 522 & 750 & 53 & 0.73 & 1.26 & 1.13 & 14.9 \\
\hline & & Ave. & 501 & 728 & 45 & 0.70 & 1.20 & 1.11 & 11.8 \\
\hline & \multirow{4}{*}{ Pipe } & Min. & 554 & 670 & 44 & 0.77 & 1.076 & 1.053 & 6.6 \\
\hline & & Max. & 640 & 770 & 52 & 0.85 & 1.158 & 1.077 & 8.4 \\
\hline & & Ave. & 552 & 729 & 48 & 0.82 & 1.107 & 1.063 & 7.4 \\
\hline & & Required & $530-630$ & $625-770$ & API & 0.86 & 1.070 & 1.033 & 6.0 \\
\hline
\end{tabular}


Charpy V-Notch Impact (CNV) tests on the steel plate were carried out at $-20^{\circ} \mathrm{C}\left(\mathrm{CNV}_{-20}\right)$. The $\mathrm{CNV}_{-20}$ absorbed energy is from $210 \mathrm{~J}$ to $452 \mathrm{~J}$ with an average value of $320 \mathrm{~J}$. Figure 1 displays $\mathrm{CNV}_{-10}$ values along the line pipe weld seam respectively in the base material $(\mathrm{BM})$, the heat affected zone (HAZ) and the welding materials (WM). The $\mathrm{BM} \mathrm{CNV}_{-10}$ is from $215 \mathrm{~J}$ to $406 \mathrm{~J}$ with an average of $282 \mathrm{~J}$. In the HAZ, $\mathrm{CNV}_{-10}$ value is between $130 \mathrm{~J}$ to $324 \mathrm{~J}$ with an average of 238J, complying with the requirement of single value larger than $60 \mathrm{~J}$ while the average no less than $80 \mathrm{~J}$. $\mathrm{CNV}_{-10}$ of the $\mathrm{WM}$ is from $125 \mathrm{~J}$ to $222 \mathrm{~J}$, with an average at 175J.

Figure 2 displays CNV test results across the girth weld joint. Tensile strength across the weld is from $660 \mathrm{MPa}$ to $677 \mathrm{MPa}$, averaging $670 \mathrm{MPa}$. $\mathrm{CNV}_{-10}$ test values across the girth weld joint reveal averages $153 \mathrm{~J}$ and $225 \mathrm{~J}$ respectively in the weld metal and the HAZ, as shown in Figure 2. Table 3 displays girth welding parameters.

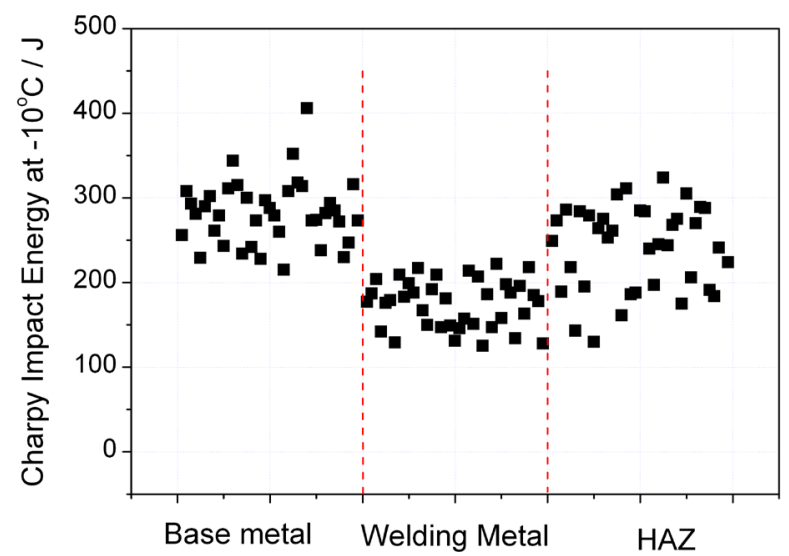

Figure 1. $\mathrm{CNV}_{-10}$ along the line pipe weld seam

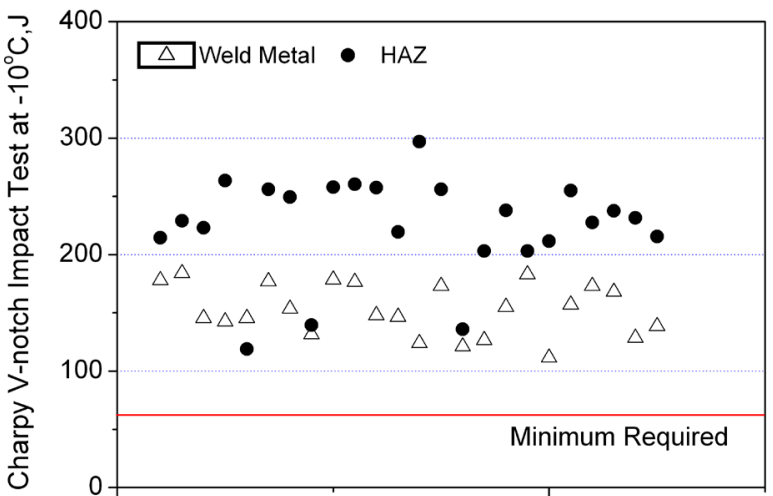

Figure 2. $\mathrm{CNV}_{-10}$ across girth weld joint
Table 3. Girth welding conditions of $\mathrm{X} 80$ line pipe

\begin{tabular}{ccc}
\hline Welding Method & Weld Consumables & Conditions \\
\hline & FABSHIELD X80 & Current: 230 to $260 \mathrm{~A}$ \\
& $\Phi 2.0 \mathrm{~mm}$ & Voltage: 21 to $22 \mathrm{~V}$ \\
& & Speed: $130-200 \mathrm{~mm} / \mathrm{min}$ \\
GMAW+FCAW-S & & Preheating Temperature: \\
& JC-30Ф2.0mm & 90 to $100^{\circ} \mathrm{C}$ \\
& & Pass Temperature: 60 \\
& & to $80^{\circ} \mathrm{C}$ \\
SMAW & BOHLER FOX & Preheating Temperature: \\
& $\Phi 3.2 \mathrm{~mm}$ & $90-100^{\circ} \mathrm{C}$ \\
& & Pass Temperature: \\
& & $60-80^{\circ} \mathrm{C}$ \\
\hline
\end{tabular}

The shearing area (SA\%) value of the Drop Weight Tear Test (DWTT) is from $85 \%$ to $95 \%$ with an average $90 \%$ at $0^{\circ} \mathrm{C}$ on the line pipe material, exceeding the required value of $75 \%$. DWTT on the steel plate at $-15^{\circ} \mathrm{C}$ shows that the SA\% value is from $85 \%$ to $95 \%$ with an average of $92 \%$.

\section{Hardening Behaviors of the Studied Grade X80 Pipeline}

Fine Grain Microstructure of the Grade X80 Pipeline Steel Materials by TEM. Figure 3 illustrates microstructures of the steel materials in the line pipe by Transmission Electron Microscope (TEM). Polygonal and/or quasi-polygonal ferrite and acicular ferrites characterize the fine grain structure of the steel where density dislocation and small size precipitates distribute at the grain boundaries and along the inner grain. Precipitates in small sizes are uniformly distributed in the polygonal ferrites shown in Figure 3 (a). In the ferrite grain, dislocation density is relatively low. The arrow in Figure 3(a) depicts the slip band. Dislocation slip reduces the intra-granular dislocation density. The sub-crystal is formed by dislocation accumulation that is one of the important ways to work hardening. Figure 3(b) shows lath ferrite structure with high density of dislocation which forms dislocation group and the sub-crystals. It can be seen in Figure 3(b) that precipitates disseminate in the lath ferrite strip with less on the grain boundary. Figure 3(c) and (d) displays the martensite/austenite $(\mathrm{M} / \mathrm{A})$ islands distributed between the ferrite structure. The dislocation density in the $\mathrm{M} / \mathrm{A}$ island is higher than in the ferrite surrounded. Precipitates are also found inner the $\mathrm{M} / \mathrm{A}$ islands lath.

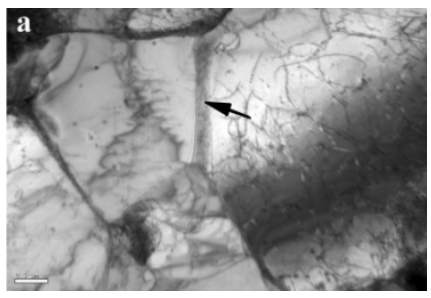

(a) polygonal ferrite;

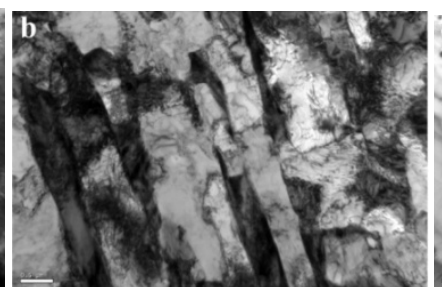

(b) lath ferrite structure;

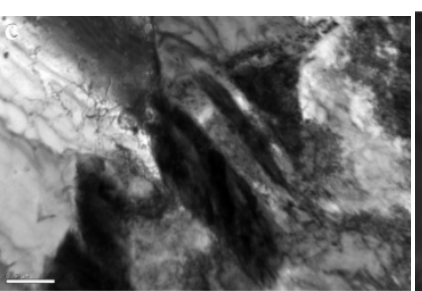

(c) MA bright field;

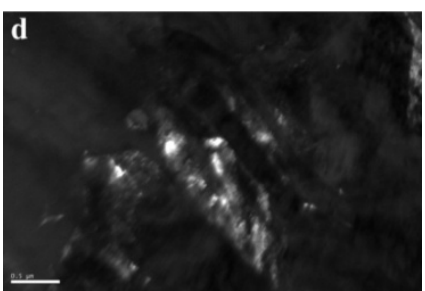

(d) MA dark field

Figure 3. Dislocation and microstructure of $\mathrm{X} 80$ in the fine grain microstructure by TEM. 
Dislocation Hardening Behavior. It is well accepted that dislocation density has crucial effect on the strength and ductility of the pipeline materials. The higher dislocation density makes higher yield strength but less materials ductility and toughness [19]. Positron Annihilation occurs mostly at vacancy, dislocation and the position where nucleus density is low. As a result, the positrons will preferentially migrate into the vacancies after they are transmitted into the metal. In the present study, the author stimulated Positron Annihilation analysis to examine and analyze the dislocation hardening behavior in the pipeline steel materials. Table 4 displays the Positron Annihilation analysis results.

Table 4. Positron annihilation analysis results

\begin{tabular}{ccccccc}
\hline condition & $\tau_{1}[\mathrm{~ns}]$ & $\mathrm{I}_{1}[\%]$ & $\tau_{2}[\mathrm{~ns}]$ & $\mathrm{I}_{2}[\%]$ & $\tau_{3}[\mathrm{~ns}]$ & $\mathrm{I}_{3}[\%]$ \\
\hline plate & 0.1477 & 70.24 & 0.4264 & 24.33 & 1.808 & 5.44 \\
pipe & 0.1531 & 70.94 & 0.4346 & 23.63 & 1.786 & 5.44 \\
\hline
\end{tabular}

Where $\tau_{1}$ is the Positron lifetime of small defects such as dislocations; $\tau_{2}$ is the Positron lifetime of large defects such as vacancy clusters, micro-cavities and micro-cracks etc.; $\mathrm{I}_{\mathrm{i}}$ is the peak number of the angular correlation curve. According to the formulae in [20], dislocation density values in the present studies are calculated to be $0.255 \times 10^{14} \mathrm{~m}^{-2}$ and $0.235 \times 10^{14} \mathrm{~m}^{-2}$ respectively for the steel plate and the pipeline materials while the dislocation hardening contributions are approximately $46.7 \mathrm{MPa}$ and $44.9 \mathrm{MPa}$ respectively. The results show that there is minor difference in dislocation density between the two materials. However, defect density such as dislocations and micro-cavities etc. in the pipe are higher in comparison to in the plate (see $\tau_{1}$ and $\tau_{2}$ values in Table 4).

Precipitation Strengthening. In the present study, distributions of precipitate were characterized by TEM, Electrolytic Chemical Phase Analysis (ECPA) and X-ray Small Angle Diffraction (X-ray SAD). Precipitates in the steel plate, including $\mathrm{M}(\mathrm{C}, \mathrm{N}), \mathrm{M}_{3} \mathrm{C}, \mathrm{CaS}$ and AlN etc., is the same as in the pipe materials with minor difference in their phase structure. The $\mathrm{M}(\mathrm{C}, \mathrm{N})$ phase constituents of steel plate and pipe materials are $\left(\mathrm{Nb}_{0.563} \mathrm{Ti}_{0.434} \mathrm{Cr}_{0.003}\right)\left(\mathrm{C}_{0.746} \mathrm{~N}_{0.254}\right)$ and $\left(\mathrm{Nb}_{0.583} \mathrm{Ti}_{0.415} \mathrm{Cr}_{0.002}\right)\left(\mathrm{C}_{0.770} \mathrm{~N}_{0.230}\right)$ respectively. The mass fraction of $\mathrm{M}(\mathrm{C}, \mathrm{N})$ is $0.0757 \%$ in the steel plate and $0.0799 \%$ in the pipe materials. All the $\mathrm{M}_{3} \mathrm{C}$ precipitates in both materials have orthogonal structure characterized as $\left(\mathrm{Fe}_{0.802} \mathrm{Mn}_{0.081} \mathrm{Ni}_{0.077} \mathrm{Cr}_{0.040}\right)_{3} \mathrm{C}$ with a mass fraction of $0.0258 \%$ for the steel plate materials and $\left(\mathrm{Fe}_{0.771} \mathrm{Mn}_{0.100} \mathrm{Ni}_{0.090} \mathrm{Cr}_{0.039)_{3}} \mathrm{C}\right.$ for the pipe materials with a mass fraction of $0.0225 \%$. The Niobium and Titanium carbonitrides have Face-centered cubic structure (FCC). Mass volumes of Aluminum nitrides and $\mathrm{CaS}$ are very small in both materials. From above, $\mathrm{Mn}, \mathrm{Ni}, \mathrm{Cr}$ and $\mathrm{Cu}$ are found as solid solution except for a minority of them existing in the $\mathrm{M}(\mathrm{C}, \mathrm{N})$ and $\mathrm{M}_{3} \mathrm{C}$.

Figure 4 displays the morphology of precipitates in both materials. Figure 5 illustrates the diffraction patterns of typical precipitates. In Figure 4, most of the precipitates less than $60 \mathrm{~nm}$ in size are uniformly distributed in the ferrite grain. Precipitates larger than $100 \mathrm{~nm}$ are mostly distributed at the grain boundaries. The precipitates in Figure 5 characterize similar element configuration even though they appear in different forms. Niobium and Titanium are the elementary chemical compositions in these precipitates. Precipitates in Figure 5(c) and (d) display similar diffraction patterns that are attributed to carbonitride of Niobium and Titanium.
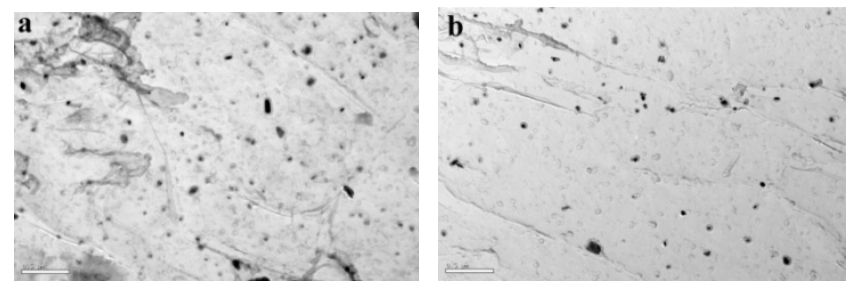

Figure 4. Morphology of precipitates in both materials. The steel plate; (b) The pipe materials
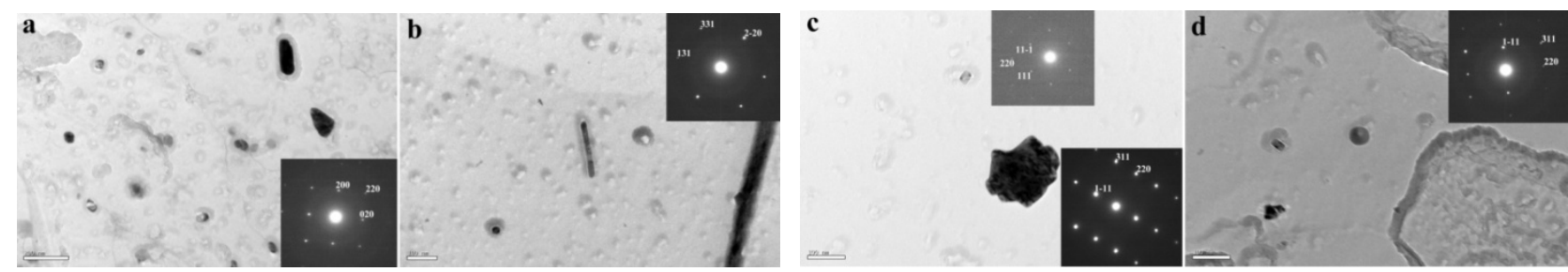

Figure 5. Diffraction patterns of typical precipitates. (a) rod-like precipitate; (b) precipitate of strip type; (c) precipitate in square and irregular form; (d) round shape precipitate. 
Figure 6 displays the fraction histogram of the precipitated particle size. Particle Mass fractions and size distributions are very similar for both materials. Based on the Taylor hardening model [21], the precipitation strengthening contribution is approximately $76.6 \mathrm{MPa}$ in the steel plate and $70.45 \mathrm{MPa}$ in the pipe materials.
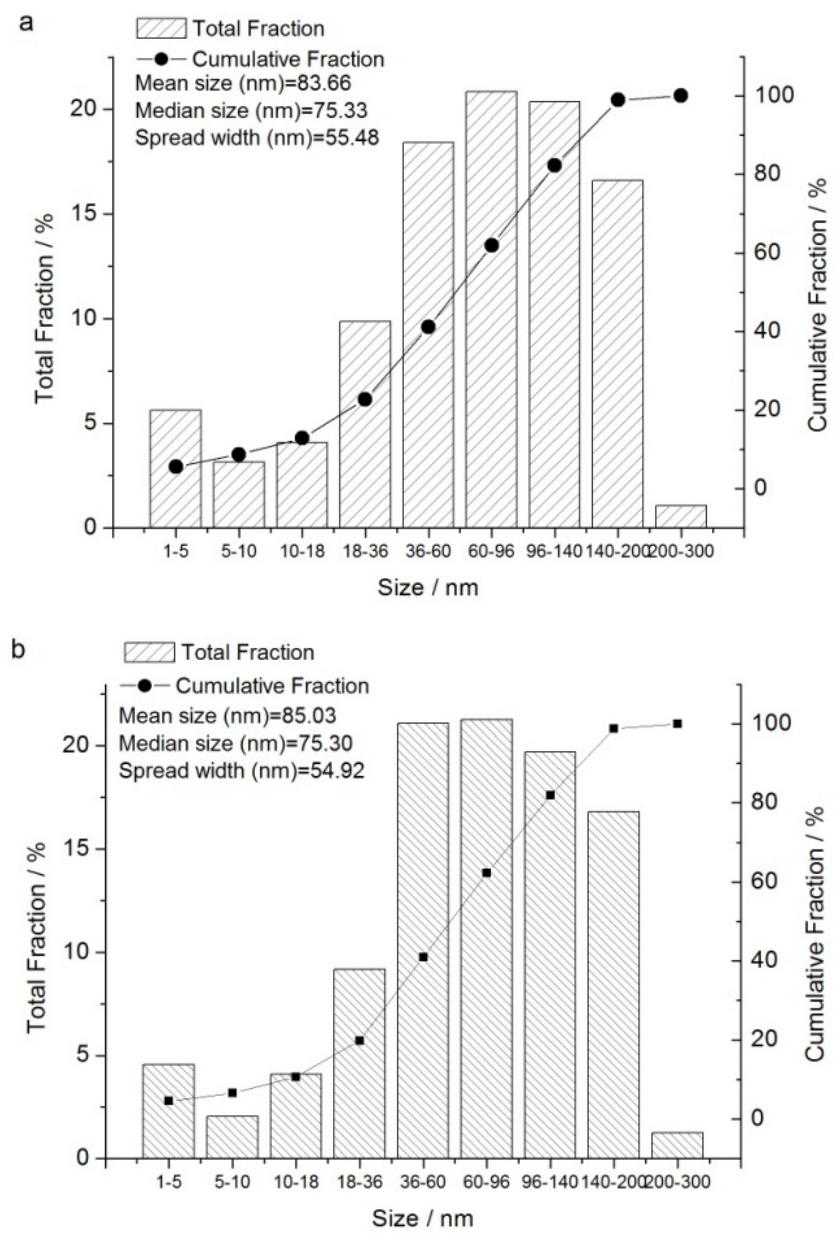

Figure 6. The precipitated particle size mass fraction. (a) the steel plate; (b) the pipe materials

\section{Summary}

Grade X80 steel was produced by careful chemical composition design and steel processing. UOE pipes with $1219 \mathrm{~mm}$ outer diameter were manufactured with the steel plates. Mechanical properties of the pipe base materials along with the girth weld joint comply with the requirements for strain based designing of pipeline construction.

The Grade X80 steel is characterized as polygonal ferrite and granular bainite with M/A constituent. Most of the precipitates less than $60 \mathrm{~nm}$ in size are uniformly distributed along the inner ferrite grain while the precipitates larger than $100 \mathrm{~nm}$ are mostly distributed at the grain boundaries. Niobium and Titanium carbonitrides attribute to the $\mathrm{M}(\mathrm{C}, \mathrm{N})$ and $\mathrm{M}_{3} \mathrm{C}$. Most $\mathrm{Mn}, \mathrm{Ni}, \mathrm{Cr}$ and $\mathrm{Cu}$ are found as solid solutions except for a minority of them existing in the $\mathrm{M}(\mathrm{C}$,
$\mathrm{N})$ and $\mathrm{M}_{3} \mathrm{C}$. The precipitation strengthening contribution is approximately $76.6 \mathrm{MPa}$ in the steel plate and $70.45 \mathrm{MPa}$ in the pipe materials.

Dislocation strengthening appears to be $46.7 \mathrm{MPa}$ and 44.9MPa in the present steel and pipe respectively. Defect density such as dislocations and micro-cavities in the pipe is higher in comparison to that in the plate.

\section{Acknowledgements}

The first author is grateful to the Taishan Scholarship of Shandong Province, China.

\section{REFERENCES}

[1] D. Belato Rosado, W. De Waele, D. Vanderschueren, S. Hertelé, Latest Developments in Mechanical Properties and Metallurgical Features of High Strength Line Pipe Steels, http://ojs.ugent.be/index.php/SCAD/issue/view/130.

[2] Stijn Hertelé, PhD Thiesis: Coupled Experimental-Numerical Framework for the Assessment of Strain Capacity of Flawed Girth Welds in Pipelines. University of Gent, May 2012

[3] J. Shimamura, M. Okatsu, N. Ishikawa, K. Nishimura1,Y. Murakami, S. Tsuyama, R. Muraoka, Material Design Concept in Heavy Wall X100 High Strength Linepipe Steel, in: Proceedings of the Twenty-first (2011) International Offshore and Polar Engineering Conference, Maui, Hawaii, USA, June 19-24, 2011:33-38.

[4] N. Ishikawa, S. Endo, J. Honda, Development of Ultra-High Strength Line pipes with Dual-Phase Microstructure for High Strain Application, JFE Technical Report, No. 7 (Jan. 2006):20-26.

[5] N. Ishikawa, N. Shikanai, J. Konda, High Performance UOE Linepipes: JFE Technical Report, No. 12 (Oct. 2008):15-19.

[6] J. Malcolm Gray, Niobium in Pipeline Steels, in: Cao shengli ed., A Collection of Translated Papers on Niobium Science and Technology. Beijing: The Chinese Metallurgical Industry Press, Beijing, 2003: 557.

[7] J. Hammond, High Strength Pipeline Standardization and Specification, in: Proc. of International Seminar on Development, Specification and Welding of High Strength Pipeline. Beijing, 2006:3.

[8] L. Meyer, History of Niobium as a Microalloying Element, in: Cao shengli ed., A Collection of Translated Papers on Niobium Science and Technology. Beijing: The Chinese Metallurgical Industry Press, Beijing, 2003: 231.

[9] K. Hulka, J. M. Gray, High Temperature Deformation of Pipeline, in: Cao shengli ed., A Collection of Translated Papers on Niobium Science and Technology. Beijing: The Chinese Metallurgical Industry Press, Beijing, 2003:368.

[10] R. Rittmann, K. Freier, Production of Niobium Microalloyed Pipeline Steel Strips, in: Cao shengli ed., A Collection of Translated Papers on Niobium Science and Technology. Beijing: The Chinese Metallurgical Industry Press, Beijing, 
2003: 357 .

[11] L.E. Collins, Niobium Microalloyed Steels produced by Steckel mill rolling, in: Cao shengli ed., A Collection of Translated Papers on Niobium Science and Technology. Beijing: The Chinese Metallurgical Industry Press, Beijing, $2003: 330$.

[12] F. Heisterkamp, T. Carneiro, Future Technology and Marketing of Niobium, in: Cao shengli ed., A Collection of Translated Papers on Niobium Science and Technology. Beijing: The Chinese Metallurgical Industry Press, Beijing, 2003:699.

[13] K. Jonsson, D. Ivey, H. Henein, S. Nafisi, The effect of Microstructure on the Mechanical Properties of X80 Microalloyed Steel, Iron and Steel Technology, (8) 2012:127-133.

[14] N. Ishikawa, M. Okatsu, S. Endo, N. Shikanai, R. Muraoka, J. Kondo, Mechanical and Metallurgical Properties of Grade X80 High Strain Linepipe Produced by Heat Treatment On-line Process, in: Proc. of the Eighteenth (2008) International Offshore and Polar Engineering Conference, Vancouver, BC, Canada, July 6-11, 2008

[15] M. Okatsu, T. Shinmiya, N. Ishikawa, S. Endo, J. Kondo, Development of High Strength Linepipe with Excellent Deformability, in: Proc. of OMAE2005 24th International
Conference on Offshore Mechanics and Arctic Engineering (OMAE 2005), June 12-17, 2005, Halkidiki, Greece:1-8

[16] A. Liessem, M. K. Graef, G. Knauf, U. Marewski, Influence of thermal treatment on mechanical properties of UOE linepipe, in: Proc. of the international Pipeline Technology Conference, Ostend, Belgium, vol. 1, pp. 1263-1281, 2004.

[17] Y. Shinohara, T. Hara, E. Tsuru, H. Asahi, Y. Terada, N. Doi, Change of Mechanical Properties of High Strength Line Pipe by Thermal Coating Treatment, Proc. of OMAE2005 24th International Conference on Offshore Mechanics and Arctic Engineering (OMAE 2005), June 12-17, 2005, Halkidiki, Greece: $1-8$

[18] H. Shitamoto, M. Hamada, S. Okaguchi, N. Takahashi, N. Yamamoto, I. Takeuchi, S. Fujita, Effect of thermal aging on deformability of X80 SAW Pipes, in: Pipeline Technology Conference, Ostend, 12-14 October 2009:1-14.

[19] https://en.wikipedia.org/wiki/Dislocation

[20] T. Ungar, L. Li, G. Tichy, W. Pantleon, H. Choob and P. K. Liawb, Work softening in nanocrystalline materials induced by dislocation annihilation. Scripta Materialia, 64 (2011), 876-879.

[21] Y.F. Shena, C.M. Wang, X. Sun, A micro-alloyed ferritic steel strengthened by nanoscale precipitates, Materials Science and Engineering A, 528 (2011), pp 8150-8156. 